extreme tenuity, others were dense and bright, hiding the stars over which they passed. The sky in the end was covered with a light haze, which condensed into a cloud canopy. No prismatic colours were visible, streamers, beams, and rays throughout being alike of a pure white light, though greatly luminous, so as to retain di: tin stive individuality in the face of brilliant moonlight. Thursday, early morn, sun shining through a hazy sky, wind light from the south; 9 a.m., overcast; II a.m., rainfall set in. Continuous all the day. Sharp fall of barometer. Thermometer mid-day, 65, wind inclined to back to the eastward. Considering that the vernal and autumnal equinoxes are the usual periods of auroral activity, and that there is yet a month to the 2Ist of September, an instance, now of auroral energy is somewhat out of the usual course of things. The equinoctial gales, yet earlier, set in with much rigour. Perhaps, as everything has a meaning, these phenomena presage the kind of weather which is to rule the autumn. Scarcely a summer bird remains save the swallow and martin. The swift left early. A solitary bird or a pair was observed, however, evening by evening up to the 28 th to return to the nesting place of the tribe, as loth to leave the English home. To day (Friday) continuous rain, which has prevailed all the night. Mid-day, thermometer 64 ; barometer $29^{\circ} 3$; set of wind southerly.

Worcester, September I

\section{Habits of Spiders}

YoUR correspondent, Mr. Frank Rowbotham, in his letter on the "Habits of Spiders" (vol. xxvi. p. 386), gives it as his opinion that a spider shakes the web from a desire "to effect concealment when it feels danger is near." I am inclined to think it does so from a feeling of anger. During a long residence in the tropics, I often amused myself irritating spiders and watching their conduct. I noticed that they generally seized the web and shook it up and down in the manner described by your correspondent, but some of the spiders were of so great a size as to render concealment by such a manceuvre quite hopeless, and I attributed their behaviour to other motives. They appeared to me more to resemble angry monkeys than anything else. I have not unfrequently seen the latter when annoyed jumping up and down on all fours with their tails erect in the air, or if confined in a cage seize the bars bp their hands and feet and shake them as the spiders did their webs.

W. J. C.

Torçuay, August 30

\section{THE RESPIRATORY MOVEMENTS OF INSECTS}

THE respiratory movements of some of the larger insects are quite apparent, and have been described by various observers. A German naturalist, Herr Rathke, published in $\mathrm{I} 86 \mathrm{I}$ a memoir in which he compared those movements, observed with the naked eye and a magnifying glass, in insects of all the principal types.

According to M. Plateau (who has lately studied the subject, and has made a preliminary communication of his results to the Belgian Academy), though Rathke's memoir is very remarkable, he overlooked many details, and fell into sundry errors, owing to the difficulty of the inquiry.

Haussmann ( 1803 ) suggested a method of indicating the movements of dilatation and contraction of an insect's abdomen, by oscillations of a liquid column; but he recognised that it would apply only to articulata of large size, and it seems incapable of yielding very exact results.

M. Girard (1873) proposed encasing the insect's abdomen with a thin envelope of caoutchouc having a style attached which would inscribe the movements.

It is a form of the graphic method that $M$. Plateau first adopted. He confined himself to perfect insects, and directed his attention to (I) the form of the inspiration and expiration; (2) the parts of the body participating in the respiratory movements; (3) the expiratory and inspiratory muscles; $(4)$ the influence of certain parts of the nervous system on the movements of respiration. The technical processes concerning the muscles and nervous system are a matter of mere dissection, once the form of respiratory movement is ascertained, and the latter, therefore, chiefly claims notice in a simple résumé.

M. Plateau used two kinds of styles to inscribe the movements on a rotating blackened cylinder. One was a narrow light strip of Bristol paste-board, fastened to the part of the body whose movement was to be ascertained, with a little Canada balsam; the other a lever of the third order, turning freely about a horizontal axis placed at one end, and resting by its own weight, at a point near the axis, on the body of the insect (the insect, in either case, being supported fixedly in any desired position).

The graphic method is, however, unsatisfactory, and sometimes quite inapplicable, and M. Plateau used another along with it, viz. the method by projection, which gave excellent results.

The insect, fixed or a small support, so that the movements in breathing are not interfered with, is introduced into a large magic lantern lit with a good petroleum lamp. A reversed silhouette is obtained on the screen, and if a certain magnification be not exceeded (say 12 diameters), a very distinct image is produced, on which one may follow all the respiratory movements sufficiently amplified to indicate real displacements of a fraction of a millimetre. With a sheet of white paper over the image one draws the contours of the silhouette, corresponding to expiration and inspiration. Further, by changing the position of the insect, and by attaching short paper styles at parts whose movements are doubtful, a complete knowledge may be acquired of all details of the respiratory movements that characterise a given insect.

With a little practice, not only may the respiratory movements of small insects, such as flies, be easily studied thus, but a number of questions are unmistakably settled, which cannot be decided by direct observation.

The following is a brief résumé of the author's results :-

I. There is no close relation between the form of the respiratory movements of an insect, and the insect's place in zoological classifications. The respiratory movements are similar only when the structure of the abdominal rings and the arrangement of muscles moving them are nearly the same. Among curious facts here, the movements of Phryganeidæ are unlike those of nearly related Neuroptera (such as Sialis), and like those of sting-bearing Hymenoptera.

2. In all insects the diameter of the abdomen diminishes in expiration by approximation of the dorsal and sternal arches of the segments; in some cases the dorsal, in others the sternal, showing the greater mobility; and in others both having nearly the same mobility.

3. The modifications in the vertical diameter may be accompanied by changes in the transversal diameter (e.g. Libellulæ).

4. Contrary to a former view, the changes of length of the abdomen, in normal respiration, by protrusion and return of the rings, are rare in insects; they are observed in an entire group only in the case of the sting-bearing Hymenoptera. Some isolated cases occur in the other zoological subdivisions (e.g. the caddis flies among the Neuroptera).

5. In the majority of cases, the thoracic segments do not participate in the respiratory movements of insects at rest. But the respiratory displacements of the posterior rings are less rare than Rathke supposed.

6. It has been thought that the respiratory movements in many insects were progressive, and propagated like a wave either from the base of the abdomen towards the point, or from the middle towards the two ends. This wave is, however, an exceptional phenomenon, is absent in all Coleoptera, in Acridians, in Libellulæ, in stingbearing Hymenoptera, in Muscides, and a part of Lepidoptera, and only appears in isolated furms in certain groups. 